\title{
INTERACTIONS BETWEEN MORPHOLOGICAL AND PHYSIOLOGICAL PLASTICITY OPTIMIZE ENERGY ACQUISITION IN CORALS
}

\author{
Mia O. Hoogenboom, ${ }^{1}$ Sean R. Connolly, and Kenneth R. N. Anthony ${ }^{2}$ \\ ARC Centre of Excellence for Coral Reef Studies and School of Marine and Tropical Biology, \\ James Cook University, Townsville, Queensland 4811 Australia
}

\begin{abstract}
Morphological plasticity in response to environmental heterogeneity may be performance enhancing or may simply result from an intrinsic instability in morphology during development. Although patterns of morphological change are well documented for numerous taxa, it is often unclear whether this plasticity enhances the performance of organisms in the habitat to which they have acclimatized. Reef-building corals are an ideal model system in which to investigate this question. We here develop a three-dimensional geometric model and present a comprehensive photosynthesis data set with experimentally calibrated photosynthesis models that predicts energy acquisition by foliose corals as a function of colony shape. This allows us to assess the extent to which changes in colony morphology along an environmental gradient track the predicted optimal colony morphologies. Our results provide strong evidence that phenotypic plasticity in foliose corals optimizes photosynthetic energy acquisition and is not simply a mechanism to increase light capture. We show that the optimal morphology is constrained at the boundaries of the environmental gradient, with non-optimal morphologies in these habitats having greatly reduced energy acquisition. However, at the center of the environmental gradient, flexibility in photophysiology allows energy acquisition to be very similar for multiple morphologies. Our results highlight the importance of phenotypic plasticity at multiple scales. Variation in overall morphology is important at niche boundaries at which conditions are consistently more stressful, whereas physiological flexibility is important in intermediate and less predictable habitats in which a rapid and reversible response to environmental fluctuations is required.
\end{abstract}

Key words: coral; light intensity gradient; optimal morphology; phenotypic plasticity; photoacclimation; photosynthesis; three-dimensional light acquisition model.

\section{INTRODUCTION}

The adaptive significance of phenotypic plasticity (i.e., variation in the expression of a genotype in relation to an environmental influence; sensu Bradshaw 1965) has captured the interest of researchers for decades. It is generally understood that the potential benefits of plasticity are linked to environmental heterogeneity (Stearns 1989, Via et al. 1995). Specifically, plasticity can be advantageous when dispersal occurs between local populations that occupy varying habitats (Kingsolver et al. 2002, Sultan and Spencer 2002) and when the range of phenotypes produced through plasticity is at least equal to that achievable through genetic differentiation (de Witt et al. 1998). In other words, plasticity is advantageous because it allows organisms to assume the morphology most suited to their immediate habitat (e.g., de Witt et al. 1998, Alpert and Simms

Manuscript received 2 August 2007; accepted 24 August 2007. Corresponding Editor: R. B. Aronson.

${ }^{1}$ Present address: Centre Scientific de Monaco, Avenue Saint-Martin 98000 Monaco.

E-mail: mia.hoogenboom@gmail.com

2 Present address: ARC Centre of Excellence for Coral Reef Studies, and Centre for Marine Studies, University of Queensland, Brisbane 4067 Australia.
2002). Although phenotypic plasticity is well documented for a range of taxa (e.g., butterflies, Kingsolver 1995; frogs, van Buskirk 2002; plants, Dong 1995, Dudley 1996; and reef-building corals, Willis 1985, Bruno and Edmunds 1997), the observed change in phenotype is not always advantageous. Although some changes in morphology appear to be performance enhancing, others are inconsequential and may simply result from flexibility in the way organisms grow during development (e.g., Schlichting 1986, Stearns 1989, Meyers and Bull 2002).

For photosynthetic organisms, the benefits of plasticity have primarily been related to resource acquisition (e.g., Dustan 1975, Hutchings and de Kroon 1994, Grime and Mackey 2002). For plants in shaded habitats, plasticity can enhance resource acquisition by increasing the area of photosynthetic tissue or by promoting leaves into higher light environments to reduce inter- and intraspecific competition (Dong 1995, Dudley and Schmitt 1996, van Kleunen and Fischer 2001, Steinger et al. 2003). In addition, plasticity in the distance between aggregations of leaves and roots can increase the proportion of biomass within favorable habitat patches (e.g., de Kroon and Hutchings 1995). Nonetheless, the optimal morphology in a given habitat is not always obvious. For example, shade plants may decrease 
TABLE 1. Phenotypically plastic corals: extent of morphological variation and environmental cue.

\begin{tabular}{|c|c|c|c|c|}
\hline Species & Morphology & Plastic trait & Cue & Reference \\
\hline Acropora cuneata & $\begin{array}{l}\text { columnar, } \\
\text { encrusting }\end{array}$ & columnar growth & light, sedimentation, hydrodynamics & 1 \\
\hline Acropora formosa & branching & secondary branching & light, hydrodynamics & $2 \Leftrightarrow$ \\
\hline Acropora palifera & $\begin{array}{l}\text { columnar, } \\
\text { encrusting }\end{array}$ & column dimensions & light, sedimentation, hydrodynamics & 1 \\
\hline Agaricia agaricites & foliose & plate dimensions/spacing & light & 3 \\
\hline Agaricia tenuifolia & foliose & plate/branch spacing & light, hydrodynamics & 4 \\
\hline Colpophyllia natans & massive & angle of growth & light & 3 \\
\hline Dichocoenia stokesii & massive & angle of growth & light & 3 \\
\hline Diploastrea heliopora & massive & corallite structure & light & $5 \Leftrightarrow$ \\
\hline Favia speciosa & massive & corallite structure & light & $5 \Leftrightarrow$ \\
\hline Madracis mirabilis & digitate & branch spacing & hydrodynamics & $6 \Leftrightarrow$ \\
\hline Meandrina meandrites & massive & angle of growth & light & 3 \\
\hline Montastrea annularis & massive & corallite structure & light, sedimentation, hydrodynamics & $7 \Leftrightarrow$ \\
\hline Montastrea annularis & massive & angle of growth & light & $8 \Leftrightarrow$ \\
\hline Montastrea cavernosa & massive & corallite structure & light, sedimentation, hydrodynamics & $9 \Leftrightarrow$ \\
\hline Montipora verrucosa & submassive & angle of growth & light, sedimentation, hydrodynamics & 10 \\
\hline Mycetophyllia spp. & plating & skeletal ridge formation & light, hydrodynamics & 11 \\
\hline Pocillopora damicornis & branching & branch diameter and spacing & hydrodynamics & 12,13 \\
\hline Pocillopora meandrina & branching & branch diameter and spacing & light, sedimentation, hydrodynamics & \\
\hline Porites astreoides & massive & angle of growth & light & $3,14,15 \Leftrightarrow$ \\
\hline Porites compressa & branching & branch length and spacing & light, sedimentation, hydrodynamics & 10 \\
\hline Porites cylindrica & branching & branch diameter & hydrodynamics & 16 \\
\hline Porites sillimaniani & $\begin{array}{c}\text { branching, } \\
\text { massive }\end{array}$ & presence of branches & light & $17 \Leftrightarrow$ \\
\hline Siderastrea siderea & massive & corallite structure & light, sedimentation, hydrodynamics & $7 \Leftrightarrow$ \\
\hline Synaraea convexa & branching & branch dimensions & light & 18 \\
\hline Turbinaria mesenterina & foliose & angle of growth & light & $19 \Leftrightarrow$ \\
\hline
\end{tabular}

Notes: Numbered references are: 1, Potts (1978); 2, Oliver et al. (1983); 3, Roos (1967); 4, Helmuth et al. (1997); 5, Todd et al. (2004); 6, Bruno and Edmunds (1997); 7, Foster (1979); 8, Graus and McIntyre (1982); 9, Foster (1983); 10, Maragos (1972); 11, Danaher (1998); 12, Lesser et al. (1994); 13, Kaandorp and Sloot (2001); 14, Brakel (1983); 15, Gleason (1992); 16, Rex et al. (1995); 17, Muko et al. (2000); 18, Jaubert (1981); and 19, Willis (1985). The double-ended arrows denote that reciprocal transplant experiments were carried out.

their canopy height and adopt a more horizontal growth direction to enhance light capture (O'Connell and Kelty 1994), or they may increase stem length in an effort to move leaves away from shading competitors (Dudley and Schmitt 1996, van Kleunen and Fischer 2001). These examples demonstrate that very different morphological strategies may be adopted in response to similar environmental gradients. For all organisms, a range of interacting biotic and abiotic factors determines which morphological strategy most benefits performance. In this study we use a combination of laboratory experiments, field observations, and mathematical modeling to investigate the extent to which photosynthetic energy acquisition drives morphological variation in a species of reef-building coral.

Reef-building corals are an ideal model system in which to investigate the performance consequences of morphological variation. Corals inhabit a range of environments (e.g., Vermeij and Bak 2002), disperse larvae over large distances (Ayre and Hughes 2004), and display pronounced morphological variability (see Table 1). Although corals vary greatly in colony architecture, many species exhibit a trend of increasing "openness" as light availability decreases, for example, in deep water. Analogous to resource acquisition being the principal explanation for plasticity in plants, growth form variation in corals has been proposed as a mechanism to maintain energy acquisition across a gradient of decreasing energy availability (i.e., colonies adopt a flat/open morphology in deep water in order to increase light interception; Dustan 1975, Jaubert 1981, Gleason 1992). However, this hypothesis does not explain why flat morphologies do not persist in high-light environments, nor does it predict where along the depth gradient the shift in morphology would occur or how rapid the transition between alternative morphologies would be. There is now some indication that detrimental effects of exposure to excessive light may cause colonies to adopt self-shading morphologies in shallow habitats (e.g., Kühl et al. 1995, Winters et al. 2003). However, it remains unclear whether these factors relating to energy acquisition adequately explain observed patterns of morphological variation. An alternative explanation is that vertically oriented growth is beneficial for reasons unrelated to light acquisition (e.g., competition for space, nutrient acquisition) and that maximizing light acquisition is only important in low-light habitats.

The principal aim of this study was to evaluate whether the observed plasticity in colony morphology for a species of foliose coral (Turbinaria mesenterina) represents a strategy to maximize energy acquisition, thereby benefiting colonies through increased energy availability for growth, reproduction, and survival. Because light intensity is the principal environmental 
correlate of colony morphology for foliose corals including our study species (Willis 1985, Helmuth et al. 1997), we focus on variation in energy acquisition across a light intensity gradient. To analyze the effects of morphological variation on colony energetics, we developed a three-dimensional light acquisition model coupled with a photosynthesis model to calculate daily net energy acquisition. To calibrate the latter model, we collected a comprehensive photosynthesis data set that accounts for within-colony flexibility in the shape of the photosynthesis-irradiance relationship due to photoacclimation (i.e., adjustment of the photosynthetic apparatus to suit average irradiance conditions; e.g., Falkowski and Raven 1997). Our approach allows us to calculate the potential energy acquisition of a range of colony morphologies for conditions under which those morphologies do not occur naturally. Therefore we are able to assess the energy implications of phenotypic plasticity by predicting the energetically optimal morphology across a depth gradient and comparing the extent to which observed morphological variation conforms to the predicted optima.

\section{Model Formulation}

\section{Study species}

Turbinaria mesenterina (Dendrophyllidae) has a wide distribution across reef types in the Indo-Pacific but occurs most abundantly in turbid coastal waters (Veron 2000). Across light habitats (e.g., with depth), colonies occur with varying degrees of openness. Specifically, the angle of the uppermost tier of the colony and the spacing between tiers change with depth (Anthony et al. 2005). Reciprocal transplant experiments between shallow and deep sites have demonstrated that this morphological variation is due to phenotypic plasticity (Willis 1985).

\section{Colony geometry}

We modeled the morphology of colonies of Turbinaria mesenterina as a series of cones nested within one another (Fig. 1). Type morphologies of T. mesenterina that are characteristic of different depths (Fig. 1A-C) were defined using an existing data set (see Anthony et al. 2005 for details). Light intensity over the colony surface was calculated using the position of points on the colony surface relative to the path of the sun across the sky. These points were defined by their location on cardinal axes defined by angle $\phi$ (in degrees, measured from south) and distance from the edge of the cone (see Appendix A). We used a fixed radius of $30 \mathrm{~cm}$ for all model colonies, approximating the average radius of colonies in our data set.

\section{Photosynthesis model}

We used the hyperbolic tangent model (Jassby and Platt 1976) to calculate photosynthesis, $p$, as a function of incident irradiance at time, $t$, over the course of the day, $E(t)$, as calculated by our light model. To take photoacclimation into account, we allow the three parameters of this model, $p_{\mathrm{MAx}}$ (the maximum rate of photosynthesis at light saturation), $E_{\mathrm{K}}$ (the irradiance at which photosynthesis is $75 \%$ of $p_{\mathrm{MAX}}$ ), and $R_{\mathrm{DARK}}$ (the rate of respiration in darkness), to depend upon growth irradiance $\left(E_{\mu}\right.$, the average irradiance experienced by the colony or region within the colony; e.g., Falkowski and Raven 1997):

$$
p[E(t), t]=p_{\mathrm{MAX}}\left(E_{\mu}\right) \tanh \left[\frac{E(t)}{E_{\mathrm{K}}\left(E_{\mu}\right)}\right]-R_{\mathrm{DARK}}\left(E_{\mu}\right) .
$$

To determine the functional relationship between the photosynthesis parameters and growth irradiance, we collected photosynthesis-irradiance $(p-E)$ data for colonies of $T$. mesenterina that had been grown under irradiances between 50 and $600 \mu \mathrm{mol}$ photons $\cdot \mathrm{m}^{-2} \cdot \mathrm{s}^{-1}$ (see Methods). We first estimated the parameters $p_{\text {MAX }}$, $E_{K}$, and $R_{\mathrm{DARK}}$ by fitting Eq. 1 to the $p-E$ curve data for each colony using a Levenberg-Marquardt nonlinear estimation routine in Statistica (StatSoft, Tulsa, Oklahoma, USA). We then used the set of fitted parameters to calibrate the relationship between $p-E$ curve parameters and growth (acclimation) irradiance (see Appendix $\mathrm{B}$ for details). Linear regression was used to describe variation in $R_{\text {DARK }}$ with growth irradiance. To model $p_{\text {MAX }}$ as a function of growth irradiance we adapted a general function developed by Platt et al. (1980) that allows for a potential decline in $p_{\text {MAX }}$ under high growth irradiances due to photoinhibition. Finally, in the absence of formal theory relating photoacclimatory state to growth irradiance, we fitted a polynomial equation (see Appendix B) to $E_{\mathrm{K}}$ estimates as a function of growth irradiance.

\section{Light model}

In our model, the intensity of incident light at a point on a colony surface (irradiance, in micromoles of quanta per square meter per second) varies according to the depth at which the colony is located, the orientation of the point relative to the path of the sun, and the position of the point within the colony as a whole. We use the Beer-Lambert law (Mobley 1994) to model the exponential decline in light intensity with depth below the water surface:

$$
E_{\mathrm{MAX}}(z)=E^{0} \exp (-k z)
$$

where $E_{\operatorname{MAX}}(z)$ is maximum total (downwelling) irradiance at depth $z, E^{0}$ is maximum daily irradiance immediately below the water surface, and $k$ describes light attenuation with depth. We incorporated variation in irradiance over the day as a sine function of time (after Marra 1978):

$$
E_{\mathrm{D}}(z, t)=E_{\mathrm{MAX}}(z) \sin \left(\frac{\pi t}{\ell}\right)^{3}
$$

where $t$ is time of day (hours since dawn), and $\ell$ is day length (12 h in our calculations). Because the photosynthesis model is parameterized from the empirical 


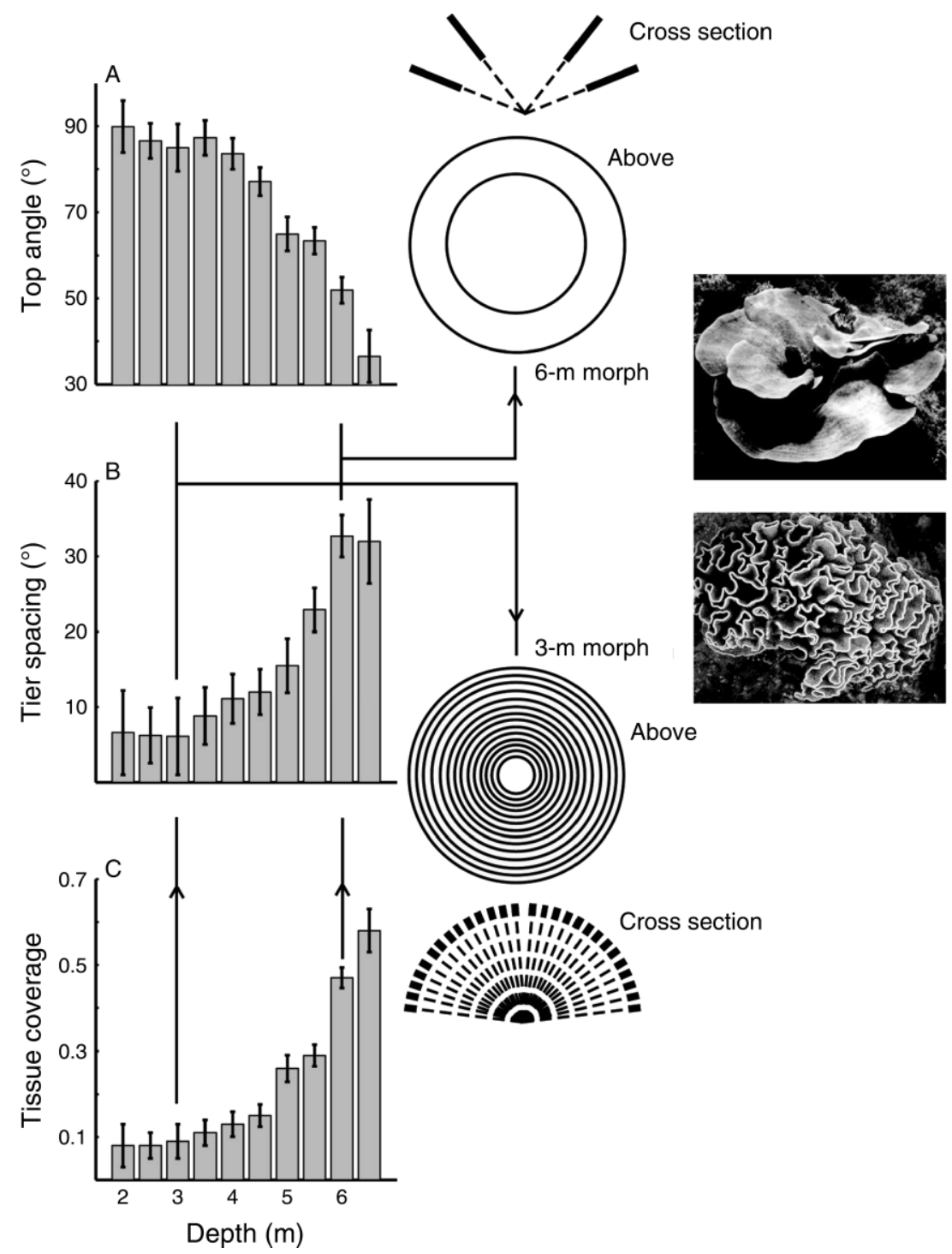

FIG. 1. Variation in colony morphology with depth for Turbinaria mesenterina at Nelly Bay: (A) angle of the top tier of the colony, (B) angular spacing between tiers, and (C) proportion of each tier that supports live tissue. Two-dimensional representations of model morphologies characteristic of 3-m and 6-m depths are shown in cross section and from above. Thick bars in cross section view depict live tissue coverage. Data are modified from Anthony et al. (2005). Errors bars represent the standard error of colony morphology for each depth category. Photos are colonies of T. mesenterina from corresponding depths in the field (photos taken by K. R. N. Anthony).

relationship between irradiance incident to coral tissue and photosynthetic oxygen evolution, it implicitly accounts for potential light-scattering effects of the coral skeleton (e.g., Enriquez et al. 2005) and variation in optical properties of the coral tissues over the colony surface.

Following the approach of other models of irradiance within complex structures (Pearcy and Yang 1995, Muko et al. 2000), we divided total irradiance into direct $\left(E_{\mathrm{D}}\right)$ and scattered $\left(E_{\mathrm{S}}\right)$ components and assumed that the scattered component of the light field was diffuse (i.e., equal intensity from all angles). We hypothesized that as total irradiance increases (e.g., moving shallower in the water column), the overall light regime will become increasingly dominated by direct light. Therefore, we model the intensity of scattered light as a nonlinear function of total irradiance (see Methods for data collection details) as

$$
E_{\mathrm{S}}(z, t)=S_{x}\left[\frac{\alpha E_{\mathrm{D}}(z, t)}{\sqrt{S_{x}^{2}+\alpha E_{\mathrm{D}}(z, t)^{2}}}\right]
$$

where $S_{x}$ defines the asymptotic intensity of scattered irradiance and $\alpha$ is the rate at which scattered irradiance approaches this maximum as total irradiance increases. 
The intensity of scattered light per angle of incidence (scattered radiance) at a given depth and time of day, $I_{\mathrm{S}}(z, t)$, is found by dividing $E_{\mathrm{S}}(z, t)$ by $\pi$ (see Appendix C).

During the day direct irradiance varies with the progression of the sun across the sky and is proportional to the cosine of the angle $(\theta)$ between the normal (perpendicular) to the colony surface and the beam of incident direct light (Mobley 1994, Falkowski and Raven 1997). The direction of the surface normal is a function of both colony steepness (the angle of each tier of the colony, $\alpha_{\mathrm{T}}$ ) and cardinal orientation (the direction that the surface faces relative to the direction of incident light, $\phi)$. Steeper sloped colonies have a surface normal that is more horizontal, so when the sun is directly overhead and direct radiance (light passing through a volume of water) is at its most intense, direct irradiance (intensity of light illuminating a surface) approaches zero $\left(\cos 90^{\circ}=0\right.$; see Appendix $\mathrm{C}$ for further explanation). Steeper sloped colonies are also self-shaded from direct radiance over a greater proportion of the day. We calculate the intensity of direct light at points on the colony surface by determining the cosine of the angle between the surface normal and the direction of incident direct light and calculating the range of angles along the path of the sun from which direct light is not shaded by other parts of the colony (see Appendix C).

Scattered irradiance is calculated from the integral of scattered radiance over the range of angles from which scattered rays may approach the colony surface (Smith and Wilson 1977). At the upper edge of the colony, scattered light may approach from within a hemisphere of angles. Moving deeper into the colony, this range of angles becomes restricted due to self-shading. Total scattered irradiance, $E_{\mathrm{S}}(z, t)$, at a point on a colony surface at depth, $z$, and time, $t$, is defined as follows:

$$
E_{\mathrm{S}}(z, t)=I_{\mathrm{S}}(z, t) \int_{\theta_{\mathrm{S}}} \int_{\phi_{\mathrm{S}}} \cos \theta_{\mathrm{S}} \sin \theta_{\mathrm{S}} d \phi_{\mathrm{S}} d \theta_{\mathrm{S}}
$$

where $I_{\mathrm{S}}(z, t)$ is the intensity of photons approaching from each angle (Appendix $C$ ), $\theta_{\mathrm{S}}$ is the angle between the surface normal and the direction of incident scattered light, and the integral over $\sin \theta_{\mathrm{S}} d \phi_{\mathrm{S}} d \theta_{\mathrm{S}}$ is effectively the surface area of the proportion of hemisphere encompassed by the range of angles (see Appendix C).

\section{Model analysis}

The complicated mathematics defining the range of angles from which light approaches colony surfaces mean that analytically integrating photosynthesis over the colony surface is not possible. Therefore, we used a numerical discretization to calculate total colony photosynthesis.

First, due to colony symmetry it is only necessary to calculate irradiance and photosynthesis for one quarter of the colony surface. Our light model equations therefore apply only to regions of the colony between cardinal angles of $0^{\circ}$ and $90^{\circ}$. To determine the appropriate increments of the discretization we analyzed the dependence of model outputs upon the size of the segments of the colony over which photosynthesis was calculated. The model converged at increments of $0.625^{\circ}$ of cardinal angle $(\phi), 0.125 \mathrm{~cm}$ increments of distance from tier edges, and time increments of $72 \mathrm{~s}$. This discretization resulted in model colonies with between 69000 and 519000 segments. All calculations were performed using the High Performance Computing facilities at James Cook University.

We used irradiance at each point of the colony surface, at each time of day, to calculate rates of photosynthesis (in micromoles of $\mathrm{O}_{2}$ per square centimeter per hour), multiplied these rates by surface area (in square centimeters; see Appendix C) and time (in hours) before summing over the colony surface to obtain gross rates of daily photosynthesis (in micromoles of $\mathrm{O}_{2}$ per day). Daily respiratory costs were likewise calculated, and the ratio of daily photosynthesis to respiration ( $p: R$ ratio) was used subsequently as a measure of net photosynthetic energy acquisition of the whole colony. Because our focus is on the relative performance of different morphologies rather than absolute carbon fixation, rates of photosynthetic oxygen evolution were not converted into units of carbon fixation (see Muscatine et al. 1981). Calculations of $p: R$ ratio were performed for each of 11 type morphologies that were generated based on the average top tier angle, number of tiers, and proportional tissue coverage of tiers that were observed in our colony morphology data set (Fig. 1), plus an additional single-tiered colony consistent with the flattest observed morphology. A gradient of light conditions, corresponding to depths between 1 and $7 \mathrm{~m}$ at the study site, was then simulated for each type morphology. Model outputs were analyzed to determine which morphology maximized photosynthetic energy acquisition at each depth.

We used Monte Carlo simulation to account for uncertainty in parameter estimates for the photosynthesis submodels. To do this, we iterated calculations of total daily energy acquisition for each morphology at each depth 200 times, each time using randomly selected parameter values from Gaussian uncertainty distributions for each photoacclimation sub-model. These distributions were generated using the best-fit parameters and variance-covariance matrix for each submodel. Finally, we compared the fit of our model prediction of optimal colony morphologies to data with that of a generalized additive model (GAM) fitted to raw (not depth-categorized) colony morphology data using Statistica's GAM module (StatSoft). The correspondence between the GAM and the optimal morphology model indicates how well the model captures the central tendency of the observed variation in morphology with depth. 


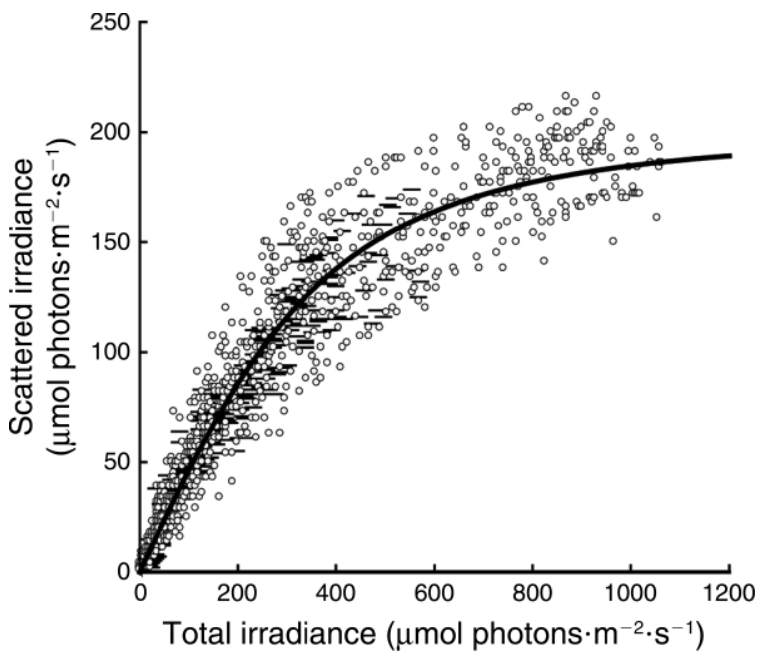

FIG. 2. Curvilinear relationship between scattered and total irradiance. The curve represents the fit of Eq. 4 to data with the parameters $S_{x}$ and $\alpha$ estimated as $292 \pm 3$ and $0.5 \pm 0.01$ (mean $\pm \mathrm{SE}$ ), respectively. $S_{x}$ defines the asymptotic intensity of scattered irradiance, and $\alpha$ is the rate of approach to this maximum as total irradiance increases. The composition of the irradiance field was the same at both $2-\mathrm{m}$ (circles) and 6-m (dashes) depths.

\section{Methods}

Fieldwork was conducted at Nelly Bay and Cockle Bay, Magnetic Island $\left(19^{\circ} 09^{\prime} \mathrm{S}, 146^{\circ} 53^{\prime} \mathrm{E}\right)$ between February 2003 and March 2005. To determine the relative contributions of direct and scattered irradiance to the total light regime at the study site we deployed pairs of light loggers (Odyssey, DataFlow Systems, Christchurch, New Zealand) at depths of $2 \mathrm{~m}$ and $6 \mathrm{~m}$ (corresponding to approximately 0 and $4 \mathrm{~m}$ below lowest astronomical tide). Light loggers were positioned so that one sensor from each pair was horizontal (measuring total downwelling irradiance) and the other was vertical and facing due south to measure scattered irradiance only.

Photosynthesis/irradiance $(p-E)$ curves were assayed using methods described by Hoogenboom et al. (2006). Briefly, flat fragments of colonies were collected from $\sim 2 \mathrm{~m}$ depth in Cockle Bay. Colonies were transported to aquarium facilities at James Cook University, divided between tanks with varying light regimes, and allowed six weeks for recovery and photoacclimation (ample for this species; Anthony and Hoegh-Guldberg 2003). Colonies were fed newly hatched Artemia nauplii daily. The water temperature and salinity within aquaria were maintained between $26.5^{\circ}$ and $28^{\circ} \mathrm{C}$ and between 34 and 36 ppt respectively, corresponding to field conditions at the time of collecting. Oxygen respirometry assays were conducted using an array of six closed, clear-perspex incubation chambers $(2.7 \mathrm{~L}$ volume) coupled with calibrated Clark-type oxygen electrodes (Cheshire Systems, Adelaide, South Australia, Australia). Oxygen concentrations were recorded every $20 \mathrm{~s}$ using a data logger (CR10X; Campbell Scientific, Brisbane, Queensland, Australia). Light regimes for photosynthesis assays and light treatments were generated using sets of metal halide lamps (each $400 \mathrm{~W}$; model EYE; Iwasaki Electronics, Tokyo, Japan) suspended above the incubation chambers and the aquaria.

\section{RESULTS}

Scattered irradiance demonstrated a curvilinear relationship with total irradiance (Fig. 2, Appendix B). The fitted model explained $94 \%$ of the variance in the data, and all parameters were significantly different from zero ( $t$ test, $\mathrm{df}=1390, P<0.05$ for $S_{x}$ and $\alpha$ ). No difference in the composition of the light field was apparent between 2- and 6-m depths at the study site (dashes vs. circles in Fig. 2). This indicates that, over the depth range considered here, the proportion of scattered light in the irradiance field depends on total light intensity rather than depth. We therefore use the fitted relationship shown in Fig. 2 to model the composition of the light field across all depths.

Photosynthesis parameters varied significantly with growth (acclimation) irradiance (Fig. 3). Although $p_{\text {MAX }}$ initially increased with increasing growth irradiance, there was a marked decline in this parameter for colonies acclimated to the highest light levels (Fig. 3A). Our photoinhibition model adequately explained this variation $\left(R^{2}=0.58\right)$, with all parameters significantly different from zero ( $t$ test, $\mathrm{df}=36, P<0.05$ for each of $p_{x}, a$, and $b$; Appendix $\left.\mathrm{B}\right)$. The linear model predicting variation in rates of respiration $\left(R_{\mathrm{DARK}}\right.$; Fig. 3B, Appendix B) explained $47 \%$ of the variance in our data with both parameters significantly different from zero ( $t$ test, $\mathrm{df}=36, P<0.05$ for both $r$ and $c$ ). Contrary to our expectations, sub-saturation irradiance, $E_{K}$, showed a hump-shaped relationship with growth irradiance (Fig. 3C).

The plasticity model captured the observed trends of increasing colony flatness and increased angular spacing between tiers with depth (Fig. 4). In general agreement with the observed pattern of variation in colony morphology, there was greater uncertainty around the predicted optimal angle and spacing at intermediate depths (increased width of the $95 \%$ confidence envelope between 5- and 7-m depths). In other words, although upright and flat morphologies were clearly optimal at shallow and deep depths respectively, at intermediate depths a wide range of morphologies had similar energy acquisition and this translated into greater uncertainty about which morphology was optimal. Therefore, at intermediate depths individual variation in photophysiology allows morphologies ranging from the most convoluted to the most open forms to be nearly energetically equivalent. Although the model appeared to underpredict the extent of colony flatness and tier spacing at intermediate depths (colonies in the field were flatter and more widely spaced than predicted; see Discussion), the GAM prediction fell within the $95 \%$ 

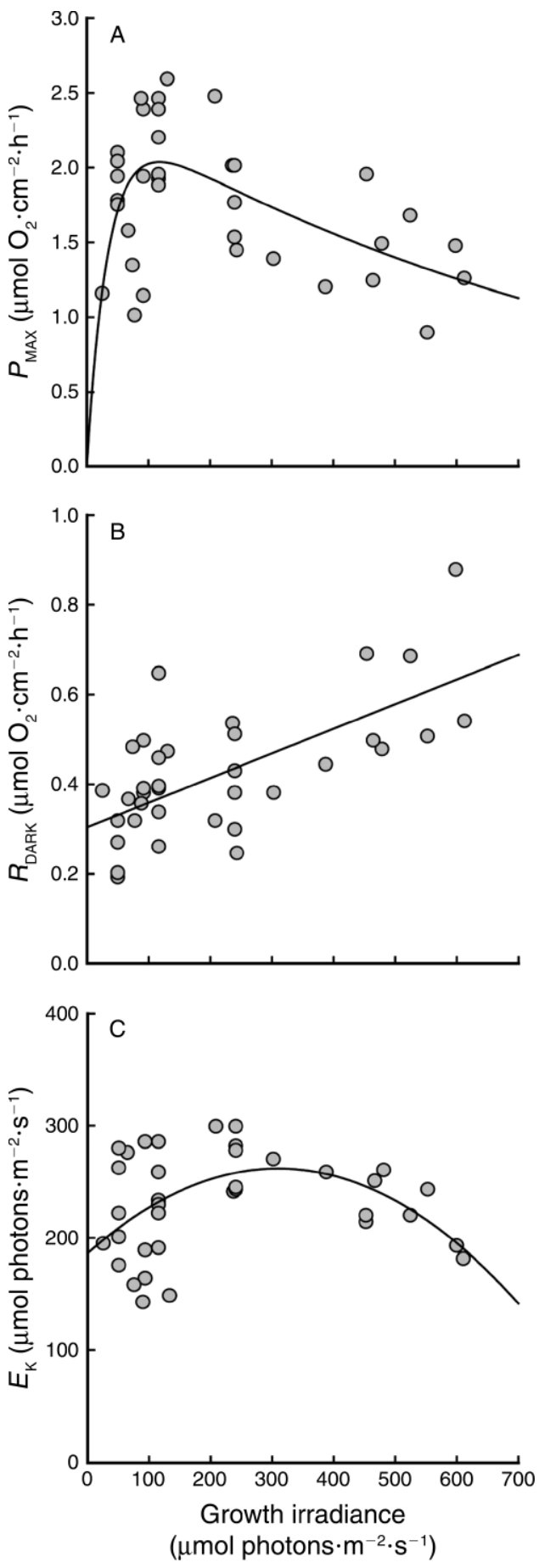

FIG. 3. Variation in parameters of photosynthesis vs. irradiance relationship for colonies of Turbinaria mesenterina acclimated to different light regimes $(n=36)$ : (A) maximum rate of photosynthesis, $p_{\mathrm{MAX}}$, (B) rate of dark respiration, $R_{\mathrm{DARK}}$, and $(\mathrm{C})$ sub-saturation irradiance, $E_{\mathrm{K}}$. confidence interval of the model predictions (dashed lines compared to shaded regions in Fig. 4A, B).

\section{Discussion}

The three-dimensional light-interception model and calibrated photoacclimation models developed in this study provide strong evidence that phenotypic plasticity in foliose corals optimizes photosynthetic energy acquisition. Moreover, our results demonstrate that maximal energy acquisition is not achieved through maximal light interception. Although flat morphologies have the highest light capture over the entire depth range, the decline in maximum rates of photosynthesis per unit area due to photoacclimation to high light means that these morphologies perform worse in shallow water than vertically oriented forms. Previous studies of morphological variation in corals have mentioned the potential importance of light stress as a driver of colony morphology (Oliver et al. 1983, Muko et al. 2000, Anthony et al. 2005). Our modeling framework quantifies the action of this mechanism and indicates that the trade-off between light capture and avoidance is an important driver of morphology. These findings are consistent with previous investigations of plant canopy structure, wherein changes in foliage orientation and increased self-shading during periods of high light intensity can significantly reduce light stress (Valladares and Pugnaire 1999, Falster and Westoby 2003).

Overall, our results show that the colony morphologies of T. mesenterina characteristic of different depths in the field are energetically optimal morphologies. However, over the middle half of the depth distribution, there is no single morphology that has markedly greater energy acquisition than others. Instead, at depths at which light intensity is neither so high as to cause damage to the photosynthetic apparatus (i.e., photoinhibition) nor so low as to be energetically limiting, small variations in the shape of the relationship between photosynthesis and irradiance allow colonies of very different shapes to have very similar energy acquisition. At these intermediate depths, the light environment fluctuates over time due to natural variation in tidal cycles and water turbidity, whereas light levels are always high at the shallow end of the depth gradient and always low in deep water (Anthony et al. 2004). The consensus view in the literature is that a stable environmental gradient that serves as a reliable cue for development of the appropriate phenotype is required in order for plasticity to be advantageous (Stearns 1989, Via et al. 1995, Meyers and Bull 2002). In variable and/or unpredictable environments (such as at intermediate depths at our study site) a capacity for rapid and reversible changes will be beneficial (Piersma and Drent 2003). Our analyses indicate that at intermediate depths, physiological flexibility (i.e., photoacclimation) equalizes differences in energy acquisition caused by variation in colony shape and may be the more important mechanism for adjusting to local conditions. Converse- 
ly, at the boundaries of the depth range, photoacclimation cannot compensate for changes in morphology, and adjustment of colony shape appears to be the dominant phenotypic response.

\section{Alternative explanations for morphological variation}

An alternative to the hypothesis that constraints related to energy acquisition are the primary driver of phenotypic plasticity in corals is that colony morphology maximizes the surface area of living tissue within the limited area of reef occupied by a colony, even where the morphology assumed reduces energy acquisition per unit surface area (e.g., Helmuth et al. 1997, Sebens 1997). In their study of the adaptive significance of plasticity in a species of irregularly branching coral, Muko et al. (2000) found support for this hypothesis, demonstrating that colony morphology in Porites sillimaniani optimized living tissue area. In contrast, our model shows that maximization of energy acquisition alone adequately captures phenotypic plasticity in $T$. mesenterina. To explain this difference, we suggest that the maximal surface area hypothesis is unlikely to apply in turbid, inshore reef habitats in which coral cover is typically low and space is unlikely to be limiting. However, this inconsistency might also be due to differences in the way that colonies with different architecture respond to variation in environmental cues: morphology in branching corals correlates with gradients of water flow velocity (e.g., Lesser et al. 1994, Bruno and Edmunds 1997), whereas morphology in foliose and massive corals appears to be more strongly correlated with light intensity (see Table 1).

A third explanation for morphological variation in corals is that colony morphology represents a passive response to the environment rather than an active choice to position resource-acquiring surfaces in areas of optimal resource availability. This hypothesis is supported by radiate accretive growth models that simulate colony morphology based on the density of nutrients arriving at different points over the colony surface (e.g., Kaandorp et al. 1996, Merks et al. 2003). These models generate realistic morphologies over hydrodynamic gradients with thick-branched colonies arising in highflow habitats because convective delivery of nutrients over the entire colony surface causes generalized rapid growth. Conversely, tall and lightly calcified morphologies arise in low-flow habitats because growth is localized at branch tips due to the formation of stagnant zones in colony interiors (e.g., Kaandorp et al. 1996). Nevertheless, water flow and the corresponding variation in nutrient and gas exchange is unlikely to explain patterns of colony morphology at our study sites where swells are only very rarely above $1 \mathrm{~m}$ in height and water turbulence is correspondingly minimal. That is, gradients in water flow velocity at sites where T. mesenterina is abundant are likely to be much too small to account for the magnitude of differences in colony shape.
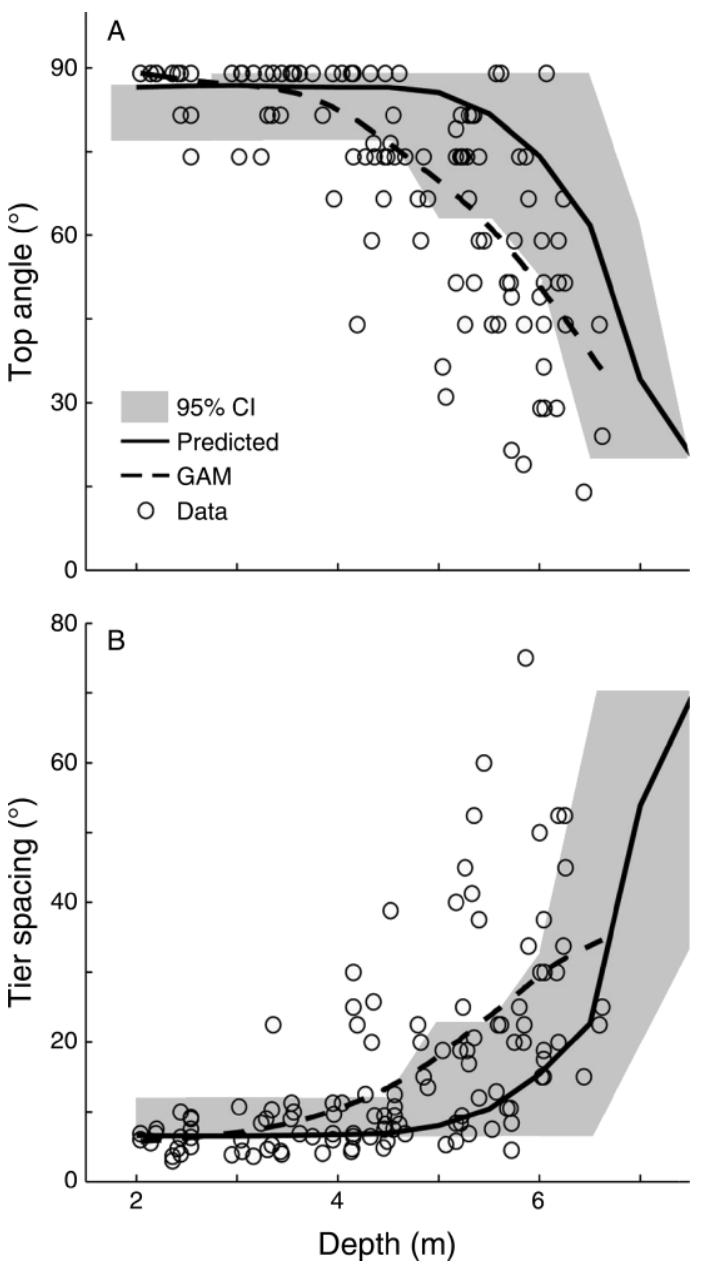

FIG. 4. Comparison of observed variation in colony morphology along a depth gradient with optimal colony morphologies predicted by the plasticity model: (A) observed and predicted top tier angle and (B) angular spacing between tiers. The solid line is the average predicted morphology, and the shaded region shows the $95 \%$ confidence interval around the average predicted morphology from 200 Monte Carlo iterations. The dashed line shows the generalized additive model (GAM) fit to the data. The open circles represent single colonies.

\section{Accuracy of model predictions}

Although the central tendency of observed colony morphology fell within the 95\% confidence band of model predictions, it was close to the lower bound of this region at intermediate depths. Therefore, the data provide some evidence that our optimality model tends to predict colony morphologies that are, on average, more upright and closely spaced than those observed in the field. There are three possible explanations for the divergence between the observed and predicted colony morphologies. Firstly, our geometric model represents colonies as regular, equally spaced sets of nested cones with equal tier length. This geometry captures trends in 
morphological change with depth for $T$. mesenterina but inevitably oversimplifies some of the variation in real colony shape. For example, tiers of colonies in deep water are rarely the same length, with upper tiers generally being shorter than lower tiers. Moreover, shallow water morphologies in the field are highly convoluted and can form vertically oriented cylinders that prevent the formation of the more horizontal lower tiers that are generated in our model colonies. Both of these factors would cause flatter morphologies generated in nature to acquire comparatively more carbon than in our model, and this could explain why some colonies in the field are flatter than the model predicts. The second possibility is that colony morphology may respond to the most energetically limiting light conditions, rather than the average conditions observed at our study site. That is, the optimal morphology predicted under average irradiance conditions at each depth may not survive during prolonged periods of low light availability (e.g., during high-turbidity events caused by run-off and/or high winds; Anthony et al. 2004). This would also cause colonies to adopt flatter morphologies than predicted by a model based on average irradiance.

A final possibility is that variation in the magnitudes of energy costs not incorporated into our model may influence colony morphology in the field. There are several potential energy sinks for corals in addition to the allocation of photosynthate between colony growth and/or reproduction, including ultraviolet light (UV), sedimentation, and temperature. Of these, only temperature can explain the tendency of the model to underestimate colony flatness for the following reasons. First, if costs related to UV exposure were a significant driver of morphology, we would expect colonies to be more vertically oriented than predicted by our model in order to reduce UV intensity, whereas we find colonies to be flatter than predicted. Second, while sediment loads represent a considerable energy burden for corals in turbid habitats (Anthony and Connolly 2004), there is no evidence to suggest that sediment effects vary between shallow and deep water. Moreover, avoidance of sedimentation would again cause colonies to be more upright than predicted in order to assist in shedding sediment (see Riegl et al. 1996). Finally, our energy acquisition model is calibrated from measurements of photosynthesis made at approximately average sea surface temperature at our study site, whereas temperatures in the field generally decrease with depth. The bell-shaped relationship between temperature and productivity is well established (Falkowski and Raven 1997), and there is evidence that low temperatures can reduce photosynthesis by limiting the rate at which light is supplied to the photosynthetic apparatus (see Staehr and Birkeland 2006). Therefore, although any temperature differential across the 6-m depth gradient at our study site is likely to be small, there is some potential for temperature effects to result in flatter colonies in the field than predicted by our optimality model.

\section{Conclusions}

Our results demonstrate that morphological plasticity for foliose corals is a mechanism to facilitate resource acquisition, as has previously been shown for other photosynthetic organisms (e.g., de Kroon and Hutchings 1995, Dong 1995). We show that energy acquisition alone adequately captures the observed variation in colony morphology for our study species. In addition, our results indicate a significant reduction in energy acquisition for flat colonies in high-light habitats, suggesting that the trade-off between light capture and avoidance previously observed in plants is also an important driver of morphology for corals. Moreover, this work demonstrates that developing the morphology appropriate for local conditions carries a greater advantage at the boundaries of the resource niche. For $T$. mesenterina, developing a self-shading, vertical colony morphology in shallow water is an important mechanism to avoid photoinhibition, whereas flat colonies have optimal energy acquisition in deep habitats in which light is limiting. Conversely, at intermediate positions along the resource axis, flexibility in photophysiology allows multiple morphologies to have comparable energy acquisition. These findings highlight the importance of phenotypic plasticity on multiple scales. Morphological variation is important at niche boundaries at which conditions are consistently more stressful, whereas physiological flexibility is important in intermediate and less predictable habitats in which a rapid and reversible response to environmental fluctuations carries additional benefits.

\section{ACKNOWLEDGMENTS}

This work was supported by funding from the Australian Research Council and James Cook University. We thank C. Glasson, F. Merida, M. Dornelas, and R. Fox for assistance with fieldwork. We thank JCU's High Performance Computing facility for providing an excellent platform. This is a contribution from the ARC Centre of Excellence for Coral Reef Studies.

\section{Literature Cited}

Alpert, P., and E. L. Simms. 2002. The relative advantages of plasticity and fixity in different environments: When is it good for a plant to adjust? Evolutionary Ecology 16:285-297.

Anthony, K. R. N., and S. R. Connolly. 2004. Environmental limits to growth: physiological niche boundaries of corals along turbidity-light gradients. Oecologia 141:373-384.

Anthony, K. R. N., and O. Hoegh-Guldberg. 2003. Kinetics of photoacclimation in corals. Oecologia 134:23-31.

Anthony, K. R. N., M. O. Hoogenboom, and S. R. Connolly. 2005. Adaptive variation in coral geometry and the optimisation of internal colony light climates. Functional Ecology 19:17-26.

Anthony, K. R. N., P. V. Ridd, A. R. Orpin, P. Larcombe, and J. Lough. 2004. Temporal variation of light availability in coastal benthic habitats: effects of clouds, turbidity and tides. Limnology and Oceanography 49:2201-2211.

Ayre, D. J., and T. P. Hughes. 2004. Climate change, genotypic diversity and gene flow in reef-building corals. Ecology Letters 7:273-278.

Bradshaw, A. D. 1965. Evolutionary signficance of phenotypic plasticity in plants. Advances in Genetics 13:115-155. 
Brakel, W. H. 1983. Depth-related changes in the colony form of the reef coral Porites astreoides: the ecology of deep and shallow reefs, Symposia Series for Undersea Research 1:2126.

Bruno, J. F., and P. J. Edmunds. 1997. Clonal variation for phenotypic plasticity in the coral Madracis mirabilis. Ecology 78:2177-2190.

Danaher, D. G. 1998. Environmental plasticity in the Caribbean coral genus Mycetophyllia (Milne-Edwards \& Haime 1848): depth and flow effects on taxonomic characters. American Zoologist 38:97A.

de Kroon, H., and M. J. Hutchings. 1995. Morphological plasticity in clonal plants: the foraging concept reconsidered. Journal of Ecology 83:143-152.

de Witt, T. J., A. Sih, and D. S. Wilson. 1998. Costs and limits of phenotypic plasticity. Trends in Ecology and Evolution 13: $77-81$.

Dong, M. 1995. Morphological responses to local light conditions in clonal herbs from contrasting habitats, and their modification due to physiological integration. Oecologia 101:282-288.

Dudley, S. A. 1996. Differing selection on plant physiological traits in response to environmental water availability: a test of adaptive hypotheses. Evolution 50:92-102.

Dudley, S. A., and J. Schmitt. 1996. Testing the adaptive plasticity hypothesis: density-dependent selection on manipulated stem length in Impatiens capensis. American Naturalist 147:445-465.

Dustan, P. 1975. Growth and form in the reef building coral Montastrea annularis. Marine Biology 33:101-107.

Enriquez, S., E. R. Mendez, and R. Iglesias-Prieto. 2005. Multiple scattering on coral skeletons enhances light absorption by symbiotic algae. Limnology and Oceanography 50:1025-1032.

Falkowski, P. G., and J. A. Raven. 1997. Aquatic photosynthesis. Blackwell Science, Malden, Massachusetts, USA.

Falster, D. S., and M. Westoby. 2003. Leaf size and angle vary widely across species: what consequences for light interception. New Phytologist 158:509-525.

Foster, A. B. 1979. Phenotypic plasticity in the reef corals Montastrea annularis (Ellis \& Solander) and Siderastrea siderea (Ellis \& Solander). Journal of Experimental Marine Biology and Ecology 39:25-54.

Foster, A. B. 1983. The relationship between corallite morphology and colony shape in some massive reef-corals. Coral Reefs 2:19-25.

Gleason, D. F. 1992. The adaptive significance of morphological plasticity in the reef coral Porites astreoides. American Zoologist 32:92A.

Graus, R. R., and I. G. McIntyre. 1982. Variation in growth forms of the reef coral Montastrea annularis (Ellis \& Solander): a quantitative evaluation of growth response to light distribution using computer simulation. Smithsonian Contributions to Marine Science 12:441-464.

Grime, J. P., and J. M. L. Mackey. 2002. The role of plasticity in resource capture by plants. Evolutionary Ecology 16:299307.

Helmuth, B. S., K. P. Sebens, and T. L. Daniel. 1997. Morphological variation in coral aggregations: branch spacing and mass flux to coral tissues. Journal of Experimental Marine Biology and Ecology 209:233-259.

Hoogenboom, M. O., K. R. N. Anthony, and S. R. Connolly. 2006. Energetic cost of photoinhibition in corals. Marine Ecology Progress Series 313:1-12.

Hutchings, M. J., and H. de Kroon. 1994. Foraging in plants: the role of morphological plasticity in resource acquisition. Advances in Ecological Research 25:159-238.

Jassby, A. D., and T. Platt. 1976. Mathematical formulation of the relationship between photosynthesis and light for phytoplankton. Limnology and Oceanography 21:540-547.
Jaubert, J. 1981. Variations of the shape and of the chlorophyll concentration of the scleractinian coral Synaraea convexa Verrill: two complementary processes to adapt to light variations. Proceedings of the Fourth International Coral Reef Symposium 2:55-58.

Kaandorp, J. A., C. P. Lowe, D. Frenkel, and P. M. A. Sloot. 1996. Effect of nutrient diffusion and flow on coral morphology. Physical Review Letters 77:2328-2331.

Kaandorp, J. A., and P. M. A. Sloot. 2001. Morphological models of radiate accretive growth and the influence of hydrodynamics. Journal of Theoretical Biology 209:257274.

Kingsolver, J. G. 1995. Fitness consequences of seasonal polyphenism in western white butterflies. Evolution 49:942954.

Kingsolver, J. G., D. W. Pfennig, and M. R. Servedio. 2002. Migration, local adaptation and the evolution of plasticity. Trends in Ecology and Evolution 17:540-541.

Kühl, M., Y. Cohen, T. Dalsgaard, B. B. Jørgensen, and N. P. Revsbech. 1995. The microenvironment and photosynthesis of zooxanthellae in scleractinian corals studied with microsensors for $\mathrm{O}_{2}, \mathrm{pH}$ and light. Marine Ecology Progress Series 117:159-172.

Lesser, M. P., V. M. Weis, M. R. Patterson, and P. L. Jokiel. 1994. Effects of morphology and water motion on carbon delivery and productivity in the reef coral, Pocillopora damicornis (Linnaeus): diffusion barriers, inorganic carbon limitation and biochemical plasticity. Journal of Experimental Marine Biology and Ecology 178:153-179.

Maragos, J. E. 1972. A study of the ecology of Hawaiian reef corals. Dissertation. University of Hawaii, Honolulu, Hawaii, USA.

Marra, J. 1978. Effect of short-term variations in light intensity on photosynthesis of a marine phytoplankter: a laboratory simulation study. Marine Biology 46:191-202.

Merks, R., A. Hoekstra, J. A. Kaandorp, and P. M. A. Sloot. 2003. Models of coral growth: spontaneous branching, compactification and the Laplacian growth assumption. Journal of Theoretical Biology 224:153-166.

Meyers, L. A., and J. J. Bull. 2002. Fighting change with change: adaptive variation in an uncertain world. Trends in Ecology and Evolution 17:551-557.

Mobley, C. D. 1994. Light and water radiative transfer in natural waters. Academic Press, San Diego, California, USA.

Muko, S., K. Kawasaki, and K. Sakai. 2000. Morphological plasticity in the coral Porites sillimaniani and its adaptive significance. Bulletin of Marine Science 66:225-239.

Muscatine, L., L. R. McCloskey, and R. E. Marian. 1981. Estimating the daily contribution of carbon from zooxanthellae to coral animal respiration. Limnology and Oceanography 26:601-611.

O’Connell, B. M., and M. J. Kelty. 1994. Crown architecture of understory and open-grown white pine (Pinus strobus L.) saplings. Tree Physiology 14:89-102.

Oliver, J. K., B. E. Chalker, and W. C. Dunlap. 1983. Bathymetric adaptations of reef-building corals at Davies Reef, Great Barrier Reef, Australia. I. Long-term growth responses of Acropora formosa (Dana 1846). Journal of Experimental Marine Biology and Ecology 73:11-35.

Pearcy, R. W., and W. Yang. 1995. A three-dimensional crown architecture model for assessment of light capture and carbon gain by understory plants. Oecologia 108:1-12.

Piersma, T., and J. Drent. 2003. Phenotypic flexibility and the evolution of organismal design. Trends in Ecology and Evolution 18:228-233.

Platt, T., C. L. Gallegos, and W. G. Harrison. 1980. Photoinhibition of photosynthesis in natural assemblages of marine phytoplankton. Journal of Marine Research 38:687-701.

Potts, D. C. 1978. Differentiation in coral populations. Atoll Research Bulletin 220:54-74. 
Rex, A. F., F. Montebon, and H. T. Yap. 1995. Metabolic responses of the scleractinian coral Porites cylindrica Dana to water motion. I. Oxygen flux studies. Journal of Experimental Marine Biology and Ecology 186:33-52.

Riegl, B., C. Heine, and G. M. Branch. 1996. Function of funnel-shaped coral growth in a high-sedimentation environment. Marine Ecology Progress Series 145:87-93.

Roos, P. J. 1967. Growth and occurrence of the reef coral Porites astreioides Lamarck in relation to submarine irradiance distribution. Dissertation. University of Amsterdam, Amsterdam, The Netherlands.

Schlichting, C. D. 1986. The evolution of phenotypic plasticity in plants. Annual Review of Ecology and Systematics 17: 667-693.

Sebens, K. P. 1997. Adaptive responses to water flow: morphology, energetics and distribution of reef corals. Proceedings of the Eighth International Coral Reef Symposium 2:1053-1058.

Smith, R. C., and W. H. J. Wilson. 1977. Photon scalar irradiance. Pages 312-316 in J. E. Tyler, editor. Light in the sea: benchmark papers in optics. Dowden Hutchinson and Ross, Stroudsburg, Pennsylvania, USA.

Staehr, P. A., and M. J. Birkeland. 2006. Temperature acclimation of growth, photosynthesis and respiration in two mesophilic phytoplankton species. Phycologia 45:468656.

Stearns, S. C. 1989. The evolutionary significance of phenotypic plasticity. BioScience 39:436-445.

Steinger, T., B. A. Roy, and M. L. Stanton. 2003. Evolution in stressful environments. II: Adaptive value and costs of plasticity in response to low light in Sinapis arvensis. Journal of Evolutionary Biology 16:313-323.

Sultan, S. E., and H. G. Spencer. 2002. Metapopulation structure favors plasticity over local adaptation. American Naturalist 160:271-283.
Todd, P. A., R. C. Sidle, and N. J. I. Lewin-Koh. 2004. An aquarium experiment for identifying the physical factors inducing morphological change in two massive scleractinian corals. Journal of Experimental Marine Biology and Ecology 299:97-113.

Valladares, F., and F. I. Pugnaire. 1999. Tradeoffs between irradiance capture and avoidance in semi-arid environments assessed with a crown architecture model. Annals of Botany 83:459-469.

Van Buskirk, J. 2002. A comparative test of the adaptive plasticity hypothesis: relationships between habitat and phenotype in anuran larvae. American Naturalist 160:87102.

Van Kleunen, M., and M. Fischer. 2001. Adaptive evolution of plastic foraging responses in a clonal plant. Ecology 82:33093319.

Vermeij, M. J. A., and R. P. M. Bak. 2002. How are coral populations structured by light? Marine light regimes and the distribution of Madracis. Marine Ecology Progress Series 233:105-116.

Veron, J. E. N. 2000. Corals of the world. Volume 2. Australian Institute of Marine Science, Townsville, Queensland, Australia.

Via, S., R. Gomulkiewicz, and G. de Jong. 1995. Adaptive phenotypic plasticity: consensus and controversy. Trends in Ecology and Evolution 10:212-217.

Willis, B. L. 1985. Phenotypic plasticity versus phenotypic stability in the reef corals Turbinaria mesenterina and Pavona cactus. Proceedings of the Fifth International Coral Reef Symposium 4:107-112.

Winters, G., Y. Loya, R. Roettgers, and S. Beer. 2003. Photoinhibition in shallow-water colonies of the coral Stylophora pistillata as measured in situ. Limnology and Oceanography 48:1388-1393.

\section{APPENDIX A}

Geometric rendition of model colonies (Ecological Archives E089-069-A1).

\section{APPENDIX B}

Summary table of parameters and equations together with best-fit parameter estimates for light and photosynthesis models (Ecological Archives E089-069-A2).

\section{APPENDIX C}

Three-dimensional geometric model of light interception by foliose corals (Ecological Archives E089-069-A3). 